\title{
Tumour response interpretation with new tumour response criteria vs the World Health Organisation criteria in patients with bone-only metastatic breast cancer
}

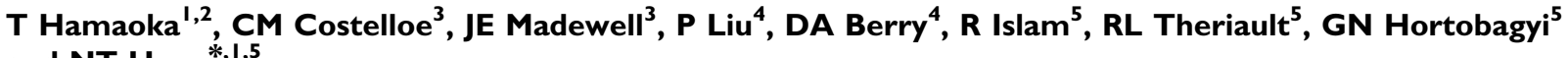 \\ and NT Ueno*,1,5
}

'Department of Stem Cell Transplantation and Cellular Therapy, The University of Texas M. D. Anderson Cancer Center, Houston, TX, USA; ${ }^{2}$ Breast Cancer, St Luke's International Hospital, Tokyo, Japan; ${ }^{3}$ Department of Diagnostic Radiology, The University of Texas M. D. Anderson Cancer Center, Houston, TX, USA; ${ }^{4}$ Department of Biostatistics and Applied Mathematics, The University of Texas M. D. Anderson Cancer Center, Houston, TX, USA; ${ }^{5}$ Department of Breast Medical Oncology, The University of Texas M. D. Anderson Cancer Center, Houston, TX, USA

BACKGROUND: We compared the utility of a new response classification (MDA; based on computed tomography (CT), magnetic resonance imaging $(\mathrm{MRI})$, plain radiography $(\mathrm{XR})$, and skeletal scintigraphy $(\mathrm{SS})$ ) and the World Health Organisation response classification (WHO; based on $\mathrm{XR}$ and $\mathrm{SS}$ ) in stratifying breast cancer patients with bone-only metastases with respect to progression-free survival (PFS), overall survival (OS), and clinical response.

METHODS: We retrospectively reviewed 4 I patients with bone-only metastatic breast cancer and assigned responses according to the MDA and WHO criteria. We analysed whether the MDA or WHO response classifications correlated with PFS and OS.

RESULTS: With the MDA criteria, there were significant differences in PFS between patients classified as responders and those classified as nonresponders $(P=0.025)$, but with the $\mathrm{WHO}$ criteria, there were not. Neither criteria distinguished responders from nonresponders in terms of OS. MDA response criteria correlated better than WHO response criteria with clinical response assessment.

CONCLUSIONS: The MDA classification is superior to the WHO classification in differentiating between responders and nonresponders among breast cancer patients with bone-only metastases. Application of the MDA classification may allow bone lesions to be considered measurable disease. Prospective study is needed to test the MDA classification among patients with bone metastasis. British Journal of Cancer (2010) I 02, 65I -657. doi:I0.1038/sj.bjc.6605546 www.bjcancer.com

Published online 26 January 2010

(c) 2010 Cancer Research UK

Keywords: bone diseases; breast neoplasms; diagnostic imaging; response assessment

Bone is one of the most common sites to which breast cancer metastasises (Coleman and Rubens, 1987; Hortobagyi, 1991). Up to $85 \%$ of patients with bone metastasis have other visceral metastases during the course of the disease (Coleman and Rubens, 1987; Hortobagyi, 1991). Skeleton-related events such as bone pain or pathologic fractures can substantially reduce the quality of life for long-term survivors (Johnson et al, 2003). Standard treatments for bone metastasis are anticancer agents, such as chemotherapy and endocrine therapy. Bisphosphonates are also used to prevent skeleton-related events. Response to treatment is typically estimated by using a combination of methods, including diagnostic imaging, measurement of biochemical markers, and evaluation of patients' symptoms.

\footnotetext{
*Correspondence: Dr NT Ueno, Department of Breast Medical Oncology, Unit 1354, The University of Texas M. D. Anderson Cancer Center, I 515 Holcombe Blvd., Houston, TX 77030, USA;

E-mail: nueno@mdanderson.org

Received 17 July 2009; revised 7 December 2009; accepted 18 December 2009; published online 26 January 2010
}

Imaging modalities such as plain radiography (XR), skeletal scintigraphy (SS), computed tomography (CT), magnetic resonance imaging (MRI), and positron emission tomography (PET) can be used to assess the response of bone lesions to treatment. However, a comprehensive strategy for assessing bone tumour response with these modalities is lacking, in part because of the complex interactions between tumour cells and host cells during bone turnover or remodeling. The presence of metastatic lesions from breast cancer can influence bone homeostasis to favour bone resorption or bone formation by affecting the activity of osteoclasts or osteoblasts, thereby resulting in osteolytic, osteoblastic, or mixed lesions. Thus, accurate assessment of the response of bone metastases to treatment requires visualising not only the tumour burden but also structural changes in the bone. Each of the aforementioned imaging techniques has advantages and disadvantages in this regard. With XR, currently the most convenient and inexpensive way of assessing treatment response, 3-6 months and $>30-50 \%$ mineral loss may be required before changes become visible (Bellamy et al, 1987; Howell et al, 1988). In addition, although XR can depict changes in bone structure, it cannot depict the tumour itself. With SS, which reflects bone blastic activity, it can also take 6 months or longer to 
Table I The UICC, WHO, and MDA criteria for detection of bone response

\begin{tabular}{|c|c|c|c|}
\hline Response type & $\begin{array}{l}\text { Union International Against Cancer } \\
\text { (UICC) }\end{array}$ & $\begin{array}{l}\text { World Health Organisation } \\
\text { (WHO) }^{\text {W }}\end{array}$ & $\begin{array}{l}\text { Revised criteria for assessment of } \\
\text { bone response (MDA) }\end{array}$ \\
\hline Target diagnostic imaging & $X R$ & $X R, S S$ & $\mathrm{XR}, \mathrm{SS}, \mathrm{CT}, \mathrm{MRI}$ \\
\hline Complete response & $\begin{array}{l}\text { Disappearance of all known disease } \\
\text { Lytic lesions should have radiologic } \\
\text { evidence of calcification }\end{array}$ & $\begin{array}{l}\text { Complete disappearance of all lesions on } \\
\text { X-ray or scan for at least } 4 \text { weeks }\end{array}$ & $\begin{array}{l}\text { Complete fill-in or sclerosis of lytic lesion on } \\
\mathrm{XR} \text { and } \mathrm{CT} \\
\text { Disappearance of hot spots or tumour } \\
\text { signal on SS, CT, or MRI } \\
\text { Normalisation of osteoblastic lesion on XR } \\
\text { and CT }\end{array}$ \\
\hline Partial response & $\begin{array}{l}\text { At least } 50 \% \text { decrease in size of measurable } \\
\text { lesions } \\
\text { Objective improvement in evaluable or } \\
\text { unmeasurable lesions } \\
\text { No new lesions or progressive lesions }\end{array}$ & $\begin{array}{l}\text { Partial decrease in size of lytic lesions, } \\
\text { recalcification of lytic lesions, or decreased } \\
\text { density of blastic lesions for at least } 4 \text { weeks }\end{array}$ & $\begin{array}{l}\text { Sclerotic rim about initially lytic lesion or } \\
\text { sclerosis of lesions previously undetected } \\
\text { on } \mathrm{XR} \text { or } \mathrm{CT} \\
\text { Partial fill-in or sclerosis of lytic lesion on XR } \\
\text { or } \mathrm{CT} \\
\text { Regression of measurable lesion on } \mathrm{XR}, \mathrm{CT} \text {, } \\
\text { or MRI } \\
\text { Regression of lesion on } \mathrm{SS} \text { (exclude rapid } \\
\text { regression }{ }^{\text {) }} \\
\text { Decrease in blastic lesion on XR or } \mathrm{CT}\end{array}$ \\
\hline $\begin{array}{l}\text { No change or stable } \\
\text { disease }\end{array}$ & $\begin{array}{l}\text { Unchanged, or between } 25 \% \text { increase and } \\
50 \% \text { decrease in size of measurable lesions }\end{array}$ & $\begin{array}{l}\text { As a result of the slow response of bone } \\
\text { lesions, the classification of 'no change' } \\
\text { should not be applied until at least } 8 \text { weeks } \\
\text { have passed from start of therapy }\end{array}$ & $\begin{array}{l}\text { No change in measurable lesion on } X R, C T \text {, } \\
\text { or } M R I \\
\text { No change in blastic lesion on } X R, C T \text {, } \\
\text { or } M R I \\
\text { No new lesion on } X R, S S, C T \text {, or } M R I\end{array}$ \\
\hline Progressive disease & $\begin{array}{l}\text { Mixed; some lesions persist while others } \\
\text { progress, or new lesions appear } \\
\text { Failure; some or all lesions progress and/or } \\
\text { new lesions appear. No lesions regress }\end{array}$ & $\begin{array}{l}\text { Increase in size of existing lesions or } \\
\text { appearance of new lesions }\end{array}$ & $\begin{array}{l}\text { Increase in size of any existing measurable } \\
\text { lesions on } \mathrm{XR}, \mathrm{CT} \text {, or } \mathrm{MRI} \\
\text { New lesion on XR, SS (excluding flare } \\
\text { phenomena), } \mathrm{CT} \text {, or MRI } \\
\text { Increase in activity on SS (excluding flare } \\
\text { phenomena) or blastic/lytic lesion on XR } \\
\text { or CT }\end{array}$ \\
\hline
\end{tabular}

Abbreviations: $\mathrm{SS}=$ skeletal scintigraphy; $\mathrm{XR}=$ plain radiography; $\mathrm{CT}=$ computed tomography; $\mathrm{MRI}=$ magnetic resonance imaging. ${ }^{\mathrm{a}} \mathrm{Criteria}$ are based on plain radiography; the duration of response is to be measured from the start of therapy until either new lesions appear or any one existing lesion increases by $25 \%$ or more above its smallest

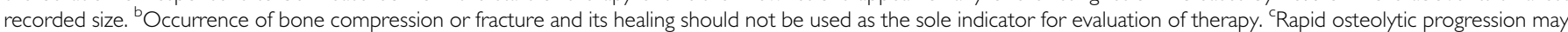
show decreased osteoblastic activity, resulting in regression of 'hot spots' on SS. XR or CT may be helpful in detecting progressive osteolysis and thus helping to identify progressive disease in this situation. If lesions that cannot be measured but are otherwise evaluable represent the bulk of disease and these lesions clearly do not respond even though measurable lesions have improved, then the response is considered no change rather than an objective regression.

reliably detect a response because of the confounding effect of the flare phenomenon, a spurious increase in radionuclide uptake because of reparative mineralisation around healing metastases (Coleman, 1991; Hortobagyi, 1991). Although CT is not commonly used to scan the whole body, CT can depict both structural changes in the bone and anatomic changes associated with the target tumour because of its multiple window settings. Magnetic resonance imaging is optimally suited for showing spinal cord status and changes in the bone marrow but not suited to showing lytic or blastic change in bone structure. FDG PET, which reflects high glucose metabolism, can be used to assess bone tumour response in osteolytic metastatic lesions ( $\mathrm{Du}$ et al, 2007), but it lacks the detail necessary to detect anatomic changes in response to treatment. Positron emission tomography-computed tomography is a new method of combining metabolic and anatomic information, but it is not yet commonly available for routine screening (Even-Sapir, 2005). Thus, proper assessment of the response of bone metastases to treatment requires consideration of different aspects of the lesions, use of diagnostic imaging modalities in appropriate combinations, and use of accurate, standardised response criteria. Unfortunately, the complexities of this process have led to the practise of considering bone lesions unmeasurable disease.

Computed tomography and MRI are now commonly used in clinical practise to assess bone tumour response, but the evidence of an advantage of these imaging modalities over conventional XR or SS is limited (Hamaoka et al, 2004). Until recently, no published response criteria included findings from diagnostic CT or MRI. The two established sets of criteria for assessing bone tumour response, one from the International Union Against Cancer (UICC) (Hayward et al, 1977) and the other from the World Health Organisation (WHO, 1979), are 30 years old and based on findings from XR or SS, which, as explained earlier, are limited in that 6 months or more may be needed before responses become visible. These criteria are not adequate as they do not incorporate modern methods (e.g., CT and MRI) of assessing the response of bone metastatic lesions to treatment. Another system in broad use, the Response Evaluation Criteria in Solid Tumours classification (Therasse et al, 2000), does not include bone lesions in response assessments. Therefore, in the absence of established response criteria, current response assessments for bone lesions using CT or MRI are highly dependent on the physician's judgment.

There is an urgent need to develop appropriate criteria for assessing tumour response in the bone because patients with bone-only metastatic disease have traditionally been excluded from clinical trials owing to the lack of such criteria. Further, the existence of an objective method with which community physicians can evaluate their patients in a timely manner and determine the effectiveness of treatment in eliciting a response in bone metastases may affect the quality of the care provided to these patients.

We hypothesised that CT or MRI is more accurate in assessing the response of bone metastatic lesions to treatment than is XR or SS because CT and MRI can visualise both bone and tumour and, presumably, changes in both that are associated with treatment (Hamaoka et al, 2004). To test this hypothesis, we compared the ability of our 'MDA classification', which takes into account findings from CT and/or MRI (Hamaoka et al, 2004) (Table 1), and 
the WHO classification, which does not, to stratify breast cancer patients with bone-only metastases with respect to progressionfree survival (PFS), overall survival (OS), and clinical response.

\section{MATERIALS AND METHODS}

This study was approved by the institutional review board of The University of Texas MD Anderson Cancer Center. We identified 46 patients with breast cancer and bone-only metastases who were observed at MD Anderson Cancer Center and given systemic treatment from October 1991 to September 2004 and who had CT, XR, SS, and/or MRI examinations available for review (a total of 180 imaging examinations). We excluded the patients who were given bisphosphonates because such treatment might affect the appearance of bone on imaging studies. Five of the 46 patients were not included in the statistical analysis because they underwent additional treatment before the first response assessment 2-6 months after the initiation of systemic therapy. All patients participated in clinical trials or standardised treatment protocols and received systemic therapy (chemotherapy in 34 patients and endocrine therapy in 7 patients). As this study focused on comparing imaging response criteria and diagnostic imaging before and after treatment, the results should not be affected by the type of treatment or chemotherapy regimen. Images were obtained at baseline (before the start of systemic therapy) and at 2-6 months after the beginning of systemic therapy and/or at 11-13 months after the beginning of systemic therapy. The broad time ranges for the two response assessment points were a result of the retrospective nature of this study. The timing of follow-up bone imaging commonly changed during the course of the study according to the tumour and treatment status.

All images were reviewed and responses assigned independently by two board-certified radiologists who specialise in musculoskeletal radiology (CMC, JEM) and who were blinded to patient identities and outcomes. A response was assigned to each imaging study (XR, SS, CT, or MRI). In addition, a response was assigned to each patient on the basis of each of the three sets of imaging response criteria (UICC, WHO, and MDA) (Table 1). The UICC criteria are based only on findings from XR, the WHO criteria include XR and SS, and the MDA criteria include findings from XR, SS, CT, and MRI (Table 1). Therefore, XR images were read three times - once in terms of the UICC criteria, again in terms of the WHO criteria, and a third time in terms of the MDA criteria. Skeletal scintigraphy images were read twice, in terms of the WHO and MDA criteria. Computed tomography and MRI scans were read only once, in terms of the MDA criteria. Responses were categorised as complete response, partial response, stable disease, or progressive disease. In total, 431 separate assessments (180 image sets) were made by each radiologist. Final responses were confirmed by consensus, with discrepant diagnoses resolved through discussion by the two readers in the presence of a third investigator. Clinical evidence of response was obtained from evaluation of (1) symptom changes, (2) trends in the levels of tumour markers, and (3) all available radiographic images. If all three criteria showed stable disease or if one or more criteria showed disease progression, the findings were interpreted as indicating no response. If one or more criteria showed response and the others were stable, the findings were interpreted as indicating a response.

To verify the advantage of the MDA criteria, we analysed whether the use of a particular imaging modality or response classification would distinguish responders from nonresponders in terms of PFS or OS by using Kaplan-Meier analyses. To analyse which particular imaging modality or response classification most accurately reflected true bone tumour response, we analysed agreement between the response assigned on the basis of imaging results (response assigned on the basis of XR, SS, CT, or MRI alone and response assigned according to the UICC, WHO, and MDA criteria) and clinical response (complete or partial response $v s$ stable or progressive disease) using McNemar's test and the kappa coefficient test.

The retrospective nature of the data collection prevented our obtaining enough XR and MRI scans for statistical analysis of XR or MRI as single modalities. Less number of XR synchronised images for each part by part, in turn precluded us from studying the UICC criteria, which are based only on XR. Less number of

Table 2 Patients' characteristics

\begin{tabular}{|c|c|}
\hline Characteristic & Number (\%) \\
\hline No. of patients & 41 \\
\hline Age, median (range) & 42 years $(3|-6|$ years $)$ \\
\hline \multicolumn{2}{|l|}{ Disease stage } \\
\hline । & $7(17)$ \\
\hline$\|$ & $21(51)$ \\
\hline III & $4(10)$ \\
\hline IV & $8(20)$ \\
\hline Unknown & $1(2)$ \\
\hline \multicolumn{2}{|l|}{ T status } \\
\hline 1 & II (27) \\
\hline 2 & $24(59)$ \\
\hline 3 & $2(5)$ \\
\hline 4 & $3(7)$ \\
\hline Unknown & I (2) \\
\hline \multicolumn{2}{|l|}{$N$ status } \\
\hline Positive & $27(66)$ \\
\hline Negative & $13(32)$ \\
\hline Unknown & I (2) \\
\hline \multicolumn{2}{|l|}{ Estrogen receptor status } \\
\hline Positive & $27(66)$ \\
\hline Negative & $13(32)$ \\
\hline Unknown & I (2) \\
\hline \multicolumn{2}{|l|}{ Progesterone receptor status } \\
\hline Positive & $24(59)$ \\
\hline Negative & $16(39)$ \\
\hline Unknown & I (2) \\
\hline \multicolumn{2}{|l|}{ Her2/neu status } \\
\hline Positive & $5(12)$ \\
\hline Negative & $13(32)$ \\
\hline Unknown & $23(56)$ \\
\hline \multicolumn{2}{|l|}{ Bone metastatic site } \\
\hline Spine & $36(88)$ \\
\hline Pelvis & $18(44)$ \\
\hline Rib & $14(34)$ \\
\hline \multicolumn{2}{|l|}{ Type of treatment } \\
\hline Chemotherapy & 34 \\
\hline Endocrine therapy & 7 \\
\hline \multicolumn{2}{|l|}{ Availability of images } \\
\hline $\begin{array}{l}\text { At baseline and at 2-6 months after treatment } \\
\text { initiation }\end{array}$ & 40 \\
\hline$X R$ images & 13 \\
\hline SS images & 37 \\
\hline CT images & 34 \\
\hline MRI images & 13 \\
\hline $\begin{array}{l}\text { At baseline and at } 11-13 \text { months after treatment } \\
\text { initiation }\end{array}$ & 25 \\
\hline$X R$ images & 11 \\
\hline SS images & 22 \\
\hline CT images & 24 \\
\hline MRI images & 12 \\
\hline
\end{tabular}

Abbreviations: $\mathrm{XR}=$ plain radiography; $\mathrm{SS}=$ skeletal scintigraphy; $\mathrm{CT}=$ computed tomography; $\mathrm{MRI}=$ magnetic resonance imaging. 
A

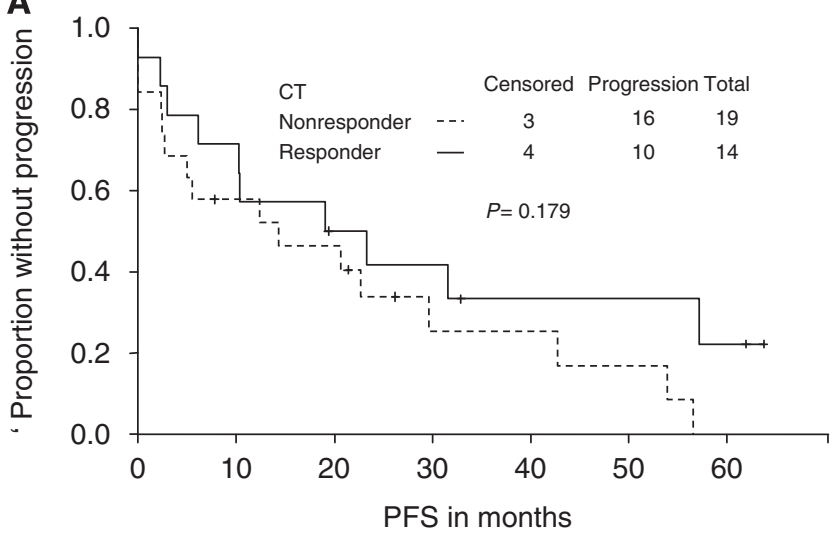

B

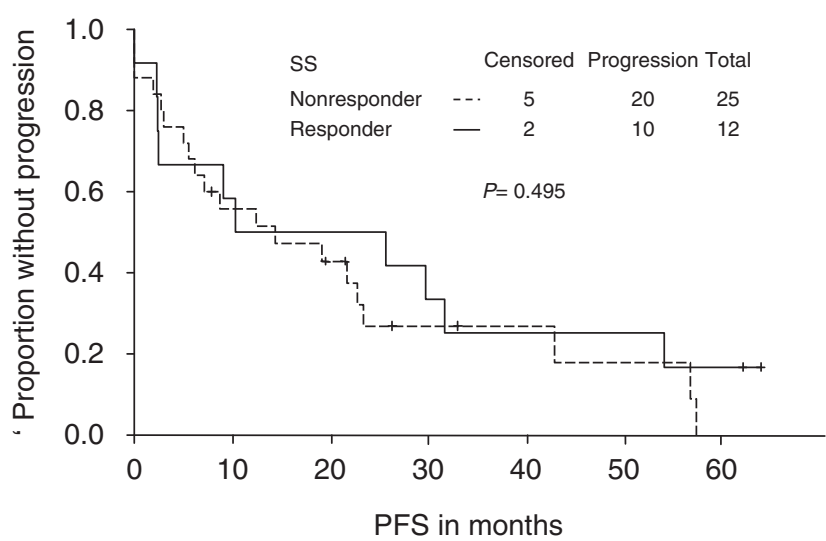

Figure I Progression-free survival (PFS) curves for patients who responded to treatment (complete or partial response) and those who did not (stable or progressive disease) according to computed tomography (CT) (A) or skeletal scintigraphy (SS) (B). CT seemed to distinguish responders from nonresponders during the first 6 months after treatment according to PFS, but SS did not.

synchronised MRI is caused, which it is not standard to assess bone tumour response. Therefore, the role of MRI was precluded from the analysis. In addition, few image sets were available from the later assessment time (at 11-13 months after treatment). Therefore, we compared CT vs SS (to compare diagnostic imaging) and the MDA classification, which includes CT, XR, and SS, vs the WHO classification, which includes XR and SS, for the period between baseline and 2-6 months after treatment had begun.

\section{RESULTS}

\section{Patient characteristics}

Patients' characteristics are shown in Table 2. The median age at diagnosis was 42 years (range, 31-61 years). We did not attempt to separate patients into lytic and blastic subgroups because most bone metastases had both lytic and blastic components. The clinical response rates at 2-6 months after treatment initiation and at 11-13 months after treatment initiation were 36.6 and $30.6 \%$, respectively. Only one patient died before 12 months after treatment initiation. The median follow-up period was 37 months.

\section{CT vs SS}

Skeletal scintigraphy alone did not distinguish responders from nonresponders in terms of either PFS (median time to progression,
Table 3 Agreement between imaging responses and clinical response

\begin{tabular}{|c|c|c|c|c|}
\hline \multirow[b]{2}{*}{$\begin{array}{l}\text { Imaging } \\
\text { response }\end{array}$} & \multicolumn{2}{|c|}{ Clinical response } & \multirow[b]{2}{*}{$\begin{array}{l}\text { McNemar's } \\
\text { test } P \text {-value }\end{array}$} & \multirow{2}{*}{$\begin{array}{c}\text { Kappa } \\
\text { coefficient } \\
+95 \% \text { Conf. Limit }\end{array}$} \\
\hline & $\begin{array}{l}\text { Non- } \\
\text { responder }\end{array}$ & $\begin{array}{c}\text { Res- } \\
\text { ponder }\end{array}$ & & \\
\hline \multicolumn{5}{|l|}{ MDA } \\
\hline Nonresponder & 16 & 2 & 0.09 & $0.53(0.27,0.79)$ \\
\hline Responder & 7 & 13 & & \\
\hline \multicolumn{5}{|l|}{ WHO } \\
\hline Nonresponder & 14 & 8 & 0.81 & $0.07(-0.24,0.39)$ \\
\hline Responder & 9 & 7 & & \\
\hline \multicolumn{5}{|l|}{$C T$} \\
\hline Nonresponder & 15 & 4 & 0.74 & $0.44(0.13,0.75)$ \\
\hline Responder & 5 & 9 & & \\
\hline \multicolumn{5}{|l|}{ SS } \\
\hline Nonresponder & 16 & 9 & 0.62 & $0.05(-0.27,0.38)$ \\
\hline Responder & 7 & 5 & & \\
\hline
\end{tabular}

Abbreviations: $\mathrm{CT}=$ computed tomography; $\mathrm{SS}=$ skeletal scintigraphy.

10.3 months for responders vs 14.3 months for nonresponders, $P=0.50$; Figure $1 \mathrm{~B}$ ) or OS (median survival time, 61.9 months for responders $v s 59.9$ months for nonresponders, $P=0.80$ ). Computed tomography alone also did not distinguish responders from nonresponders in terms of either PFS (median time to progression, 19.1 months for responders vs 14.3 months for nonresponders, $P=0.18$; Figure $1 \mathrm{~A}$ ) or OS (median survival time, 61.9 months for responders $v s 34.4$ months for nonresponders, $P=0.38$ ).

However, CT alone tended to correlate better than SS alone with true clinical response during the first 2-6 months after treatment (kappa coefficients, 0.44 and 0.05 , respectively; McNemar's $P=0.74$ and 0.62 , respectively; Table 3 ).

\section{MDA classification $v s$ WHO classification}

The MDA classification, which includes SS and CT, distinguished responders from nonresponders in terms of PFS (median time to progression, 23.3 months for responders $v s 5.5$ months for nonresponders; $P=0.025$; Figure $2 \mathrm{~A}$ ). There was also a trend for difference between responders and nonresponders in terms of OS, but this difference was not significant (median survival time, 61.9 months for responders $v s 34.4$ months for nonresponders; $P=0.13$ ).

In contrast, the WHO classification did not distinguish responders from nonresponders in terms of either PFS (median time to progression, 12.4 months for responders $v s 10.4$ months for nonresponders; $P=0.55$; Figure $2 \mathrm{~B}$ ) or $\mathrm{OS}$ (median survival time, 61.9 months for responders vs 59.9 months for nonresponders; $P=0.97)$. The MDA criteria tended to correlate better than the WHO criteria with true clinical response during the first 2-6 months after treatment (kappa coefficients, 0.53 and 0.07 ; McNemar's $P=0.09$ and 0.81 , respectively; Table 3 ).

\section{DISCUSSION}

We previously reported a new set of response criteria, the MDA criteria, that address the shortcomings of the UICC and WHO criteria by taking into account CT and MRI findings (Hamaoka et al, 2004) (Table 1). The MDA criteria also include detailed descriptions of anatomic changes to be considered for each diagnostic imaging modality. The MDA criteria take into account the fact that the structure of bone rarely heals such that the bone has the same appearance as the original even if treatment was 

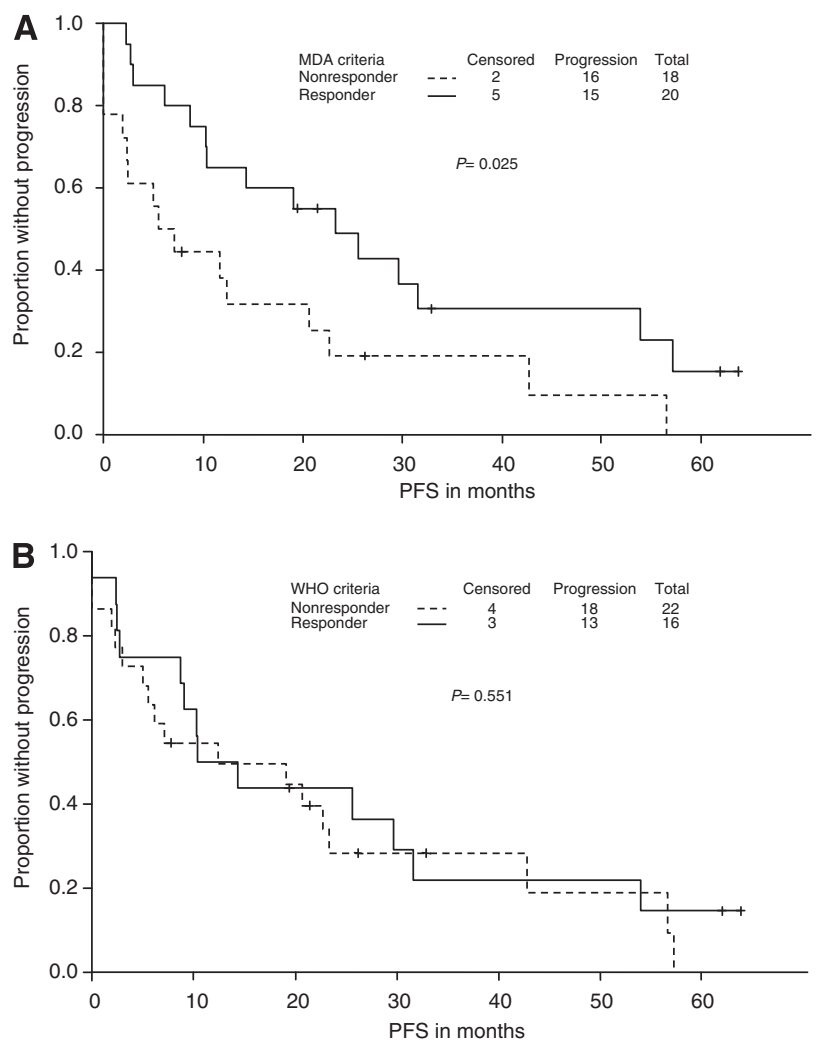

Figure 2 Progression-free survival (PFS) curves for patients who responded to treatment (complete or partial response) and those who did not (stable or progressive disease) according to the MDA criteria (A) and the World Health Organisation (WHO) criteria (B). The MDA criteria (which incorporate findings from CT scans) distinguished responders from nonresponders during the first 6 months after treatment according to PFS; in other words, patients classified as responders according to the MDA criteria (which included CT findings) had a better prognosis than did those classified as nonresponders. In contrast, the WHO classification (based on SS findings) did not differentiate between responders and nonresponders in terms of PFS.

significantly effective (complete response). For example, according to the MDA criteria, recalcification of the rim of an osteolytic lesion on XR or CT (Figure 3A) is considered partial response, and an increase in the area of lysis (Figure $3 \mathrm{~B}$ ) is considered progressive disease.

The results of this retrospective image reading analysis indicate that the MDA classification is superior to the WHO classification in differentiating between responders and nonresponders among breast cancer patients with bone-only metastases. With the MDA classification, which takes into account CT findings, there were significant differences in PFS between patients classified as responders and those classified as nonresponders within 2-6 months after treatment. With the WHO classification, which does not take into account CT findings, there were no such differences. The MDA criteria tended to be more sensitive than the WHO criteria for detecting response, although the number of cases studied was too few to permit definitive conclusions on this point. Computed tomography may be more sensitive than SS for discerning responses.

Few reports are available documenting survival outcomes according to response assessed using different response-assessment schemes. One study showed that survival rates among patients with 'stable' bone disease for more than 6 months according to the UICC criteria were similar to those among patients with a 'partial response' (Howell et al, 1988). In other words, in that study, the
UICC criteria did not distinguish between responders and nonresponders in terms of survival rates.

Despite the widespread use of CT for assessing tumour response of solid non-bone tumours, the use of CT for assessing bone tumour response has yet to be established. We did find one published prospective study in which CT was used to assess the response of lytic metastatic bone lesions in 20 patients and CT response was compared with change in patients' symptoms (Bellamy et al, 1987). In this study, improvement observed on CT was associated with improvement in symptoms in two-thirds of the patients. This study has shown that patients with a response on CT may have had longer PFS and OS than those who did not show a response.

The lower correlation between the primarily SS-based WHO criteria and response than between the MDA criteria and response could have resulted from several factors, including high falsepositive rates caused by conditions other than tumour (e.g., fracture, arthritis, infection) (Galasko and Doyle, 1972; Citrin et al, 1977; Coleman et al, 1988b; Tubiana-Hulin, 1991; Rybak and Rosenthal, 2001) or 'flare' phenomena (Coleman, 1991; Hortobagyi, 1991). In one prospective report, in $75 \%$ of patients with breast cancer whose bone metastases showed a partial response (healing of lytic metastases on XR), there was increased tracer uptake on SS during the first 3 months after treatment because of new bone that had formed during the repair process. Such a situation could well be interpreted as progressive disease; however, after 6 months, the accumulation gradually decreased (Coleman et al, 1988a). Another possible explanation for the poor correlation between WHO response and clinical response is that rapid progression of disease, when overwhelming destruction allows little chance for new bone to form, is sometimes depicted by SS as a reduction in isotope uptake ('cold spots') (Galasko and Doyle, 1972; Condon et al, 1981; Cook and Fogelman, 2000). In our opinion, determining the final response of bone metastases solely on the basis of changes in radionuclide uptake over time is not appropriate (Libshitz and Hortobagyi, 1981).

Our findings suggest that the MDA criteria, which incorporate findings from CT scans, are superior to the WHO criteria, which are based primarily on SS, for predicting PFS in patients who respond to treatment. This confirms the importance of using multiple imaging modalities to accurately determine response. We found a statistically significant difference only for the MDA-toWHO comparison for PFS. However, we speculate that the lack of significant differences in other comparisons may have been because of the limited number of patients who had multiple image sets available for retrospective image reviews. To increase the likelihood of identifying patients who had had imaging performed at regular intervals after treatment, we selected patients who had been treated according to the structured, well-organised treatment plans required of investigative research protocols; this necessarily limited the number of patients and images available for review.

In summary, the results of this image reading study suggest that the MDA classification is superior to the WHO classification for assessing the response of bone metastases to treatment. However, these findings need to be confirmed prospectively. In addition, in future prospective studies, the effect of bisphosphonates should be studied because bisphosphonates are now commonly used in patients with bone metastasis. Further, PET-CT, which fuses images from PET and CT, may yield better detection of bone tumour response because of the addition of information on glucose metabolism to the anatomic details provided by CT. One study showed $80.5 \%$ agreement between CT osteoblastic response and PET positivity change (positive to negative) in osteolytic metastases (Du et al, 2007). Positron emission tomography also has the advantage of permitting quantification of response - bone tumour response might be quantified using the maximum standard uptake value (Stafford et al, 2002). That indicates that PET can be a sensitive modality for monitoring osteolytic bone 
A
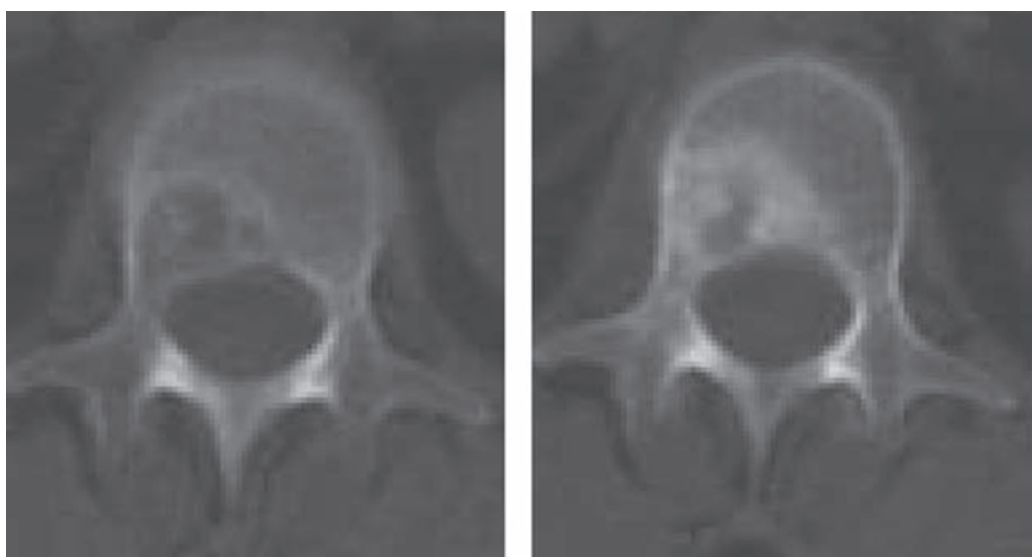

B
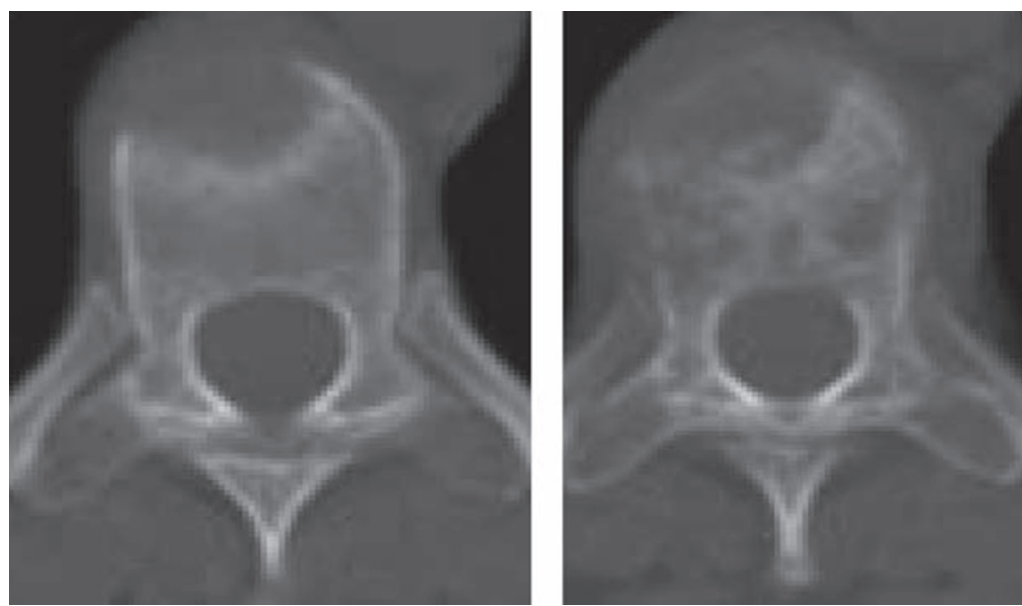

Figure 3 Computed tomography scans assessed with the MDA criteria. (A) Sclerotic change (right) in the rim of an originally lytic lesion (left) indicates a partial response. (B) Lytic progression (right) of an originally lytic lesion (left) indicates progressive disease.

tumour response. Although PET scanning has the potential to yield false-positive results with the use of granulocyte colony-stimulating factors in patients receiving myelosuppressive chemotherapy, the $\mathrm{CT}$ aspect of PET - CT may compensate for that potential problem with its anatomic information (Even-Sapir, 2005; Israel et al, 2006). As the cost of PET-CT gradually becomes more reasonable, there is a great possibility that PET-CT may become the standard for assessing the response of bone metastasis.

\section{REFERENCES}

Bellamy EA, Nicholas D, Ward M, Coombes RC, Powles TJ, Husband JE (1987) Comparison of computed tomography and conventional radiology in the assessment of treatment response of lytic bony metastases in patients with carcinoma of the breast. Clin Radiol 38: $351-355$

Citrin DL, Bessent RG, Greig WR (1977) A comparison of the sensitivity and accuracy of the $99 \mathrm{TCm}$-phosphate bone scan and skeletal radiograph in the diagnosis of bone metastases. Clin Radiol 28: 107-117

Coleman RE (1991) Assessment of Response to Treatment. Springer Verlag: London

Coleman RE, Mashiter G, Whitaker KB, Moss DW, Rubens RD, Fogelman I (1988a) Bone scan flare predicts successful systemic therapy for bone metastases. J Nucl Med 29: 1354-1359

Coleman RE, Rubens RD (1987) The clinical course of bone metastases from breast cancer. Br J Cancer 55: 61-66

Coleman RE, Rubens RD, Fogelman I (1988b) Reappraisal of the baseline bone scan in breast cancer. J Nucl Med 29: 1045-1049

\section{ACKNOWLEDGEMENTS}

We thank Christine Wogan and Stephanie Deming of the Department of Scientific Publications at M. D. Anderson Cancer Center for their expert editorial assistance. This work was supported in part by an Institutional Research Grant from The University of Texas M. D. Anderson Cancer Center (to TH and NTU) and a gift from Pfizer (to NTU).

Condon BR, Buchanan R, Garvie NW, Ackery DM, Fleming J, Taylor D, Hawkes D, Goddard BA (1981) Assessment of progression of secondary bone lesions following cancer of the breast or prostate using serial radionuclide imaging. $\mathrm{Br} J$ Radiol 54: $18-23$

Cook GJ, Fogelman I (2000) The role of positron emission tomography in the management of bone metastases. Cancer 88: 2927-2933

Du Y, Cullum I, Illidge TM, Ell PJ (2007) Fusion of metabolic function and morphology: sequential [18F]fluorodeoxyglucose positron-emission tomography/computed tomography studies yield new insights into the natural history of bone metastases in breast cancer. J Clin Oncol 25: $3440-3447$

Even-Sapir E (2005) Imaging of malignant bone involvement by morphologic, scintigraphic, and hybrid modalities. J Nucl Med 46: $1356-1367$

Galasko CS, Doyle FH (1972) The detection of skeletal metastases from mammary cancer. A regional comparison between radiology and scintigraphy. Clin Radiol 23: 295-297 
Hamaoka T, Madewell JE, Podoloff DA, Hortobagyi GN, Ueno NT (2004) Bone imaging in metastatic breast cancer. J Clin Oncol 22: $2942-2953$

Hayward JL, Carbone PP, Heusen JC, Kumaoka S, Segaloff A, Rubens RD (1977) Assessment of response to therapy in advanced breast cancer. Br J Cancer 35: 292-298

Hortobagyi GN (1991) Bone metastases in breast cancer patients. Semin Oncol 18: $11-15$

Howell A, Mackintosh J, Jones M, Redford J, Wagstaff J, Sellwood RA (1988) The definition of the 'no change' category in patients treated with endocrine therapy and chemotherapy for advanced carcinoma of the breast. Eur J Cancer Clin Oncol 24: 1567-1572

Israel O, Goldberg A, Nachtigal A, Militianu D, Bar-Shalom R, Keidar Z, Fogelman I (2006) FDG-PET and CT patterns of bone metastases and their relationship to previously administered anti-cancer therapy. Eur J Nucl Med Mol Imaging 33: $1280-1284$

Johnson JR, Williams G, Pazdur R (2003) End points and United States Food and Drug Administration approval of oncology drugs. J Clin Oncol 21: $1404-1411$
Libshitz HI, Hortobagyi GN (1981) Radiographic evaluation of therapeutic response in bony metastases of breast cancer. Skeletal Radiol 7: 159-165 Rybak LD, Rosenthal DI (2001) Radiological imaging for the diagnosis of bone metastases. Q J Nucl Med 45: 53-64

Stafford SE, Gralow JR, Schubert EK, Rinn KJ, Dunnwald LK, Livingston RB, Mankoff DA (2002) Use of serial FDG PET to measure the response of bone-dominant breast cancer to therapy. Acad Radiol 9: 913-921

Therasse P, Arbuck SG, Eisenhauer EA, Wanders J, Kaplan RS, Rubinstein L, Verweij J, Van Glabbeke M, van Oosterom AT, Christian MC, Gwyther SG (2000) New guidelines to evaluate the response to treatment in solid tumors. European Organization for Research and Treatment of Cancer, National Cancer Institute of the United States, National Cancer Institute of Canada. J Natl Cancer Inst 92: 205-216

Tubiana-Hulin M (1991) Incidence, prevalence and distribution of bone metastases. Bone 12(Suppl 1): S9-S10

World Health Organization (WHO) (1979) WHO Handbook for Reporting Results of Cancer Treatment. World Health Organization Offset Publication: Geneva (Switzerland) 